\title{
Analisis Potensi Kawasan Laiwangi Wanggameti di Taman Nasional Matalawa Untuk Arahan Pengembangan Ekowisata
}

\author{
Melvi Reimon Mangngi Tiga ${ }^{1}$, Eka Intan Kumala Putri², Meti Ekayani²
}

1Magister Pengelolaan Sumber daya Alam dan Lingkungan Institut Pertanian Bogor; e-mail: melvyreimon22@gmail.com

${ }^{2}$ Departemen Ekonomi Sumberdaya dan Lingkungan Institut Pertanian Bogor

\begin{abstract}
ABSTRAK
Pengembangan Taman Nasional sebagai kawasan ekowisata adalah salah satu altenatif untuk mengurangi degradasi kawasan konservasi di masa yang akan datang. Kawasan Laiwangi Wanggameti adalah salah satu kawasan hutan di Taman Nasiobnal Matalawa di Kabupaten Sumba Timur NTT mempunyai potensi sumberdaya alam yang layak untuk dikembangankan sebagai kawasan ekowisata. Penelitiian ini bertujuan untuk: (1) mengidentifikasi dan menganalisis potensi supply dan demand ekowisata kawasan Laiwangi Wanggameti; (2) menganalisis keinginan membayar pengunjung potensial lokal (WTP); (3) merumuskan strategi pengembangan ekowisata kawasan Laiwangi Wanggameti. Potensi ekowisata dianalisis secara deskriptif kualitatif. Contingent Valuation Method digunakan untuk menganalisis keinginan membayar dan strategi pengembangan ekowisata di kawasan Laiwangi Wanggameti menggunakan analisis SWOT. Hasil penelitian menunjukkan bahwa beberapa objek di kawasan Laiwangi Wanggameti layak untuk dikembangkan dalam pengembangan ekowisata yakni gunung Wanggameti, dataran tinggi Katikuwai, area perkemahan di Wanggameti dan Praing Kareha, air terjun Laputi, danau Laputi dan area birdwatching di Billa. Nilai keinginan membayar calon pengunjung potensial adalah sebesar Rp.13.450 per orang per tiket. Strategi pengembangan ekowisata di kawasan Laiwangi Wanggameti dilakukan melalui strategimendukung kebijakan pertumbuhan yang agresif.
\end{abstract}

Kata kunci: ekowisata, keinginan membayar, strategi

\begin{abstract}
The development of national park area as ecotourism location becomes one of alternative to minimize the degradation of conservation area in the future. The Laiwangi Wanggameti area is one of the forest areas in Matalawa National Park in East Sumba district of NTT which has the potential of natural resources that are suitable to be developed as an ecotourism area. The study aimed to: (1) identify and analyze the potential supply and demand ecotourism of Laiwangi Wanggameti area; (2) analyze the potential willingness to pay of local potential visitors (WTP); (3) formulate the strategies of ecotourism development in Laiwangi Wanggameti area. Qualitative descriptive analysis is used to analyze the ecotourism potential. The contingent valuation method is used to anlyze the willingness to pay and the ecotourism development strategies of Laiwangi Wanggameti area which formulated by using SWOT analysis. Some objects in Laiwangi Wanggameti are feasibel for ecotourism development which are: Wanggameti mountain, Katikuwai plateau, ground camping in Wanggameti and Praing Kareha, Laputi waterfall, Laputi lake, birdwatching area in Billa. The value of willingness to pay of local potential visitors is thirteen thousand four hundred fifty rupiah/person/ticket. The ecotourism development strategy in Laiwangi Wanggameti area is through a strategy of supporting aggressive growth policy.
\end{abstract}

Keywords: ecotourism, willingness to pay, strategy

Citation: Tiga, M. R.M., Putri, E. I. K., dan Ekayani, M. (2019). Analisis Potensi Kawasan Laiwangi Wanggameti di Taman Nasional Matalawa Untuk Arahan Pengembangan Ekowisata. Jurnal Ilmu Lingkungan, 17(1),32-41, doi:10.14710/jil.17.1.32-41

\section{Pendahuluan}

Kawasan hutan Laiwangi Wanggameti adalah salah satu kawasan hutan di Taman Nasional Matalawa (TN Matalawa) yang berlokasi di Kabupaten Sumba Timur propinsi Nusa Tenggara Timur. Kawasan ini merupakan daerah resapan air utama dan pengairan bagi lahan pertanian masyarakat di Kabupaten Sumba Timur.
Dengan luas sekitar 47.014 hektar kawasan ini memiliki tipe ekosistem hutan hujan tropis, hutan musim serta savanna sehingga menjadikan kawasan ini sebagai habitat berbagai jenis flora dan fauna endemik. Salah satu burung endemik Sumba yang mendiami kawasan tersebut adalah burung kakatua jambul jingga (Cacatua sulphurea citrinocristata) (Statistik TNLW 2013). 
Salah satu permasalahan yang dihadapi dalam pengelolaan kawasan konservasi termasuk Taman Nasional adalah berkaitan dengan aktivitas masyarakat dalam kawasan Taman Nasional untuk memenuhi kebutuhan hidupnya (Kadir dkk 2012). Birgantoro \& Nurrochmat (2007) menyatakkan bahwa adanya masyarakat yang tinggal di sekitar hutan yang mempunyai akses langsung maupun tidak langsung terhadap kawasan hutan dan memanfaatkan sumberdaya hutan adalah suaturealita yang tidak dapat diabaikan. Sejalan dengan hal tersebut Nurrani \& Tabba (2013)mengungkapkan bahwa kondisi ini dapat diperparah dengan rendahnya tingkat pendidikan masyarakat lokal yang rentan terhadap pengaruh budaya luar yang konsumtif. Dimana menyebabkan masyarakat tidak lagi memanfaatkan sumberdaya hutan secara arif dan bijaksana, namun cenderung melakukan perambahan dan eksploitasi yang tidak terkendali.

TN Matalawa sebagai taman nasional yang baru dibentuk, juga diperhadapkan dengan berbagai ancaman dan gangguan yang secara periodik terjadi namun belum ada penurunan yang signifikan diantaranya terkait ancaman kebakaran, penggembalaan liar, perburuan satwa, perambahan dan klaim lahan, bangunan liar pada areal perambahan, penebangan kayu serta pencurian hasil hutan non kayu (TN Matalawa 2017a). Demikian pula yang masih terjadi di segmen Laiwangi Wanggameti. Wiyanto (2011) menyatakan bahwa permasalahan yang menjadi tantangan dalam pengelolaan khususnya di segmen Laiwanggi Wanggameti adalah masih maraknya penebangan liar, perambahan, penggembalan ternak yang masuk dalam kawasan oleh masyarakat di sekitar kawasan dan ancaman kebakaran hutan yang berasal dari luar kawasan. Aktivitas masyarakat ini tentunya akan mengarah kepada terjadinya degradasi kawasan di masa yang akan datang apabila tidak diminimalisir sejak dini.

Pengembangan kawasan secara berkelanjutan menggunakan strategi ekowisata menjadi salah satu alternatif untuk meminimalisir terjadinya degradasi kawasan dimasa mendatang. Hal ini dimungkinkan karena kawasan ini memiliki potensi yang dapat dikembangkan sebagai suatu kawasan wisata terbatas. Ekowisata adalah salah satu bentuk pemanfaatan jasa lingkungan hutan yang secara ekonomi menguntungkan (economically viable), secara ekologi ramah lingkungan (environmentally benign), secara teknis dapat diterapkan (technically feasible), dan secara sosial dapat diterima oleh masyarakat (socially acceptable) (Karsudi dkk. 2010).

Ekowisata sebagai suatu perjalanan yang bertanggungjawab ke wilayah-wilayah yang masih alami ekowisata erat kaitannya dengan berbagai upaya konseravsi yang bertujuan untuk melindungi dan melestarikan lingkungan sedemikian rupa sehingga menekan sekecil mungkin dampak terhadap lingkungan dan sosial budaya, membangkitkan pendanaan bagi kawasan-kawasan yang dilindungi, serta meningkatkan kesejahteraan masyarakat lokal (Jalani 2012; Purwanto dkk. 2014; TIES 2015; Husamah dan Hudha 2018; Yuniarti et.al 2018; Widodo dkk. 2018). Jika masyarakat dapat memenuhi kebutuhan ekonominya dari keterlibatan dalam wisata alam maka mereka akan ikut menjaga kelestarian sumberdaya alam tersebut. Terjaganya kelestarian alam merupakan modal utama untuk keberlanjutan wisata alam yang artinya terjaminnya kelangsungan pendapatan masyarakat (Ekayani dkk2014).

Penelitian ini bertujuan untuk: (1) mengidentifikasi potensi suplly dan demand ekowisata kawasan Laiwangi Wanggameti; (2) menganalisis potensi Willingness To Pay (WTP) calon pengunjung potensial; (3) merumuskan strategi pengembangan ekowisata kawasan hutan Laiwangi Wanggameti di TN Matalawa.

\section{Metode Penelitian}

Penelitian dilakukan di kawasan hutan Laiwangi Wanggameti TN Matalawa di Kabupaten Sumba Timur, Propinsi Nusa Tenggara Timur. Pada bulan Desember 2017- Maret 2018.

Jenis data yang digunakan adalah data primer dan data sekunder. Data primer melalui pengamatan di lapangan serta melalui wawancara mendalam dengan para stakeholder maupun responden yang dipilih secara purposive sampling yang disesuaikan dengan tujuan penelitian. Sedangkan data sekunder meliputi keselurahan data maupun informasi yang berasal dari artikel ilmiah maupun laporan penelitin/kegiatan.

\section{Hasil dan Pembahasan}

\subsection{Potensi Supply dan Demand Ekowisata Kawasan Laiwangi Wanggameti \\ 3.1.1. Potensi Supply \\ Potensi supply ekowisata yang} diidentifikasi meliputi potensi daya tarik wisata alam, sarana wisata, aksesibilitas, informasi dan promosi.

a. Daya Tarik Wisata Alam

1. Daya Tarik Biologi

Taman Nasional Matalawa merupakan wilayah yang berada dalam gugusan kepulauan Wallacea sehingga memiliki keanekaragaman flora dan fauna yang khas. Data statistik TN Matalawa 2017 menunjukkan bahwa kawasan tersebut memiliki 375 Jenis Tumbuhan, 70 Jenis Tumbuhan Paku-Pakuan, 90 Jenis tumbuhan berkhasiat obat. Dari 357 Jenis tumbuhan yang ada di kawasan ini, 157 Jenis diantaranya dapat ditemui di kawasan hutan Laiwangi Wanggameti. Hal ini di dukung oleh beberapa tipe ekosistem yang dapat di temui di kawasan yakni ekosistem 
hutan hujan tropis, savana, hutan musim dan hutan ampupu (TNLW 2013).

Jenis-jenis flora didominasi di kawasan ini didominasi oleh Alstonia spectabilis, Canariumsp, Ficus sp, Syzygium sp, Dysoxylum sp dan Palaqium $s p$. Jenis vegetasi penciri hutan sekunder jenis yang umum dijumpai di hutan dataran rendah adalah Melochia umbelata, Ficus septica, Casuarium oleosum, Toona sureni dan Legistromea $s p$. Beberapa jenis merupakan jenis yang dilindungi dan masuk dalam kategori CITES, Appedix II, yaitu Gaharu (Grinops verstegi) dan kategori CITES Appendix I, yaitu Cendana (Santalum album) (TN Matalawa 2017b). Selain itu ada juga beberapa jenis-tumbuhan yang merupakan tumbuhan unggulan lokal yang juga dapat ditemukan di dalam kawasan antara lain: inju watu (Spondias pinata Merr), kaduru/ nyatoh (Palaquium obovatum), horani/suren (Toona sureni Merr), kesambi (Schleihesa oleosa), lobung/salam (Eugenis $s p$ ), manera (Aglaia eusideroxylon), mayela (Artocarpus glaucus BL), pulai (Alstonis scholaris), halai (Alstonis spectabilis), sawo kecik (Manilkara kauki). Selain itu ada juga jenis flora potensial sebahai bahan baku kerajinan yang cukup melimpah seperti rotan (Calamus Sp) dan pandan (Pandanus $S p$ ).

Taman Nasional Matalawa merupakan habitat yang baik untuk beberapa jenis satwa. Data statistik BTN Matalawa 2017 menunjukkan bahwa di kawasan ini dapat dijumpai 158 jenis burung, 94 jenis kupu-Kupu, 41 jenis capung, 28 jenis Mamalia, 6 Jenis Amphibi dan 30 Jenis Reptil. Diantara satwa tersebut beberapa diantara merupakan spesies endemik di kawasan ini.

Terdapat 11 spesies burung endemik yaitu: burungmadu Sumba(Cinnyris buettikoferi), Cabai Sumba (Dicaeum wilhelminae), Myzomela Sumba(Myzomela dammermani), Gemak Sumba (Turnix everetti), Punai Sumba (Treron teysmanii), Walik Rawamanu (Ptilinopus dohertyl), Sikatan Sumba (Ficedula harterti), Sikatan Coklat Sumba (Muscicapa segregate), Pungguk Sumba, (Ninox sumbaensis), Pungguk Wengi (Ninox rudolfi) dan Julang Sumba (Rhyticeros everetti). Selain itu terdapat sekitar 19 anak jenis endemik, misalnya Nuri Bayan(Eclectus roratus cornelia) dan Kakatua Sumba (Cacatua sulphurea citrinocristata).

Selain burung di kawasan hutan Laiwangi Wanggameti dapat juga ditemukan berbabagi jenis kupu-kupu dan capung. Jenis kupu-kupu yang merupakan spesies endemik/ sub endemik kawasan diantaranya Athyma karita, Athyma margarita, Cepora Julia, Charaxes elwesi, Charaxes ocellatus, Cyrestis nais, Delias fasciata, Elimnias amoena, Ideopsis oberthurii, Junonia adulatrix, Lexias aegle, Pachliopta oreon, Papilio Acheron dan Papilio neumoegenii. Terdapat 6 spesies capung yang merupakan spesies endemik di kawasan ini yakni Burmagomphus williamsoni, Drepanosticta berlandi, Hemicordulia chrysochlora,
Nososticta diadesma, Orthetrum austrosundanum, Paragomphus tachyerges (TN Matalawa 2017b).

Satwa dari keluarga mamalia dengan status konservasi least concern, near threathened maupun vulnerable yang dapat dijumpai di kawasan hutan Laiwangi Wanggameti diantaranya kalong besar (Pteropus vampirus), tikus belukar (Rattus Sp), babi hutan (Sus scrofa), musang luwak (Paradoxurus hermaphroditus), rusa timor (Cervus timorensis) dan monyet ekor panjang (Macaca fascicularis). Sedangkan satwa herpetofauna yang dapat ditemukan di kawasan ini antara lain katak sungai (Hylarana elberti), katak pohon (Litoria everetti), ular kebun Nusa Tenggara (Dendrelaphis inornatus), kadal terbang (Draco boschmai), cicak hutan (Gehyra sp), ular Piton/sanca batik (Python reticulatus) dan biawak/ Peacock monitor (Varanus sauffenbergi).

\section{Daya Tarik Fisik}

- Puncak Gunung Wanggameti

Panorama puncak gunung Wanggameti dapat menjadi salah satu daya tarik ekowisata di kawasan ini. Gunung Wanggameti adalah gunung tertinggi di Pulau Sumba yang berada dalam kawasan TN Matalawa di segmen Laiwangi Wanggameti (Gambar 1). Puncak ini memiliki ketinggian $1.225 \mathrm{~m}$ di atas permukaan laut (dpl). Dalam zonasi Taman Nasional Matalawa Gunung Wanggameti berada pada zona inti. Puncak Wanggameti dapat diakses melalui kecamatan Matawai Lapawu menggunakan kendaraan roda 4 maupun roda 2. Jarak dari ibukota Kabupaten ke puncak Wanggameti adalah $\pm 80 \mathrm{~km}$ dengan waktu tempuh sekitar 4-5 jam. Dari pintu masuk utama ke lokasi pendakian dibutuhkan waktu sekitar 15-20 menit.

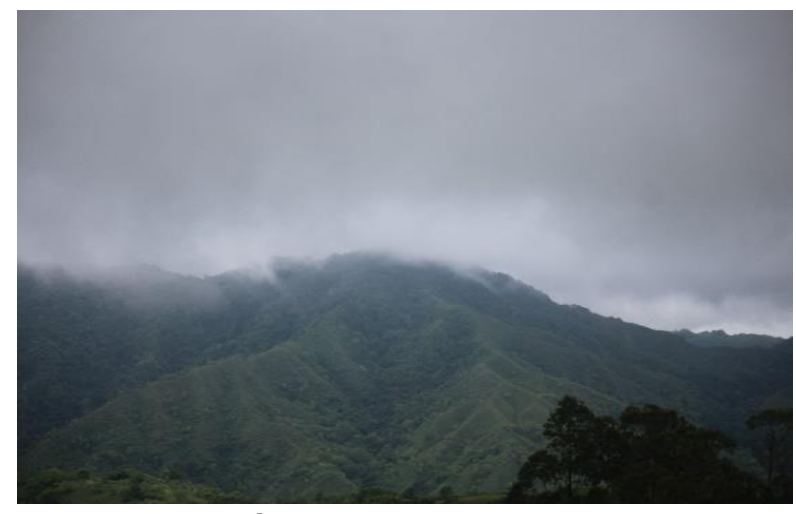

Gambar 1. Gunung Wanggameti Sumber : Dokumentasi Peneliti (2018)

Pengunjung yang memiliki minat pendakian akan masuk melalui sebuah gapura selamat datang yang berada di sebelah kiri jalan dari pintu masuk utama. Di sekitar gapura selamat datang telah dilengkapi dengan tata tertib pendakian, tanda larangan serta sebuah shelter. Akses untuk menuju ke puncak Wanggameti telah dibuat jalur tracking yang akan memudahkan para pendaki untuk sampai ke puncak. Para pendaki akan menempuh area tracking sejauh $7 \mathrm{~km}$ dari 
gapura selamat datang dengan waktu tempuh sekitar 7-8 jam.

\section{- Area Perkemahan Wanggameti (Camping ground)}

Area perkemahan tersebar di beberapa lokasi didalam kawasan. Lokasi tersebut dapat di akses melalui pintu masuk bagian timur melalui Kecamatan Matawai Lapawu atau melalui jalur masuk bagian barat yakni melalui kecamatan Tabundung (berjarak $115 \mathrm{~km}$ dari ibukota Kabupaten) dengan waktu tempuh 4-5 jam.

Lokasi perkemahan yang berada di jalur masuk bagian timur dapat diakses melalui kecamatan Matawai Lapawu. Berjarak sekitar 3 $\mathrm{km}$ dari gapura utama dengan jarak tempuh sekitar 30 menit sampai 1 jam. Di lokasi perkemahan telah disediakan 6 petak tempat yang dapat dijadikan sebagai tempat untuk pendirian tenda, dengan ukuran $3 \mathrm{~m} \times 3 \mathrm{~m}$. Ada sebuah sungai kecil yang mengalir di sekitar lokasi perkemahan yang dapat dijadikan sebagai sumber air bagi para pengunjung yang hendak berkemah di lokasi ini.

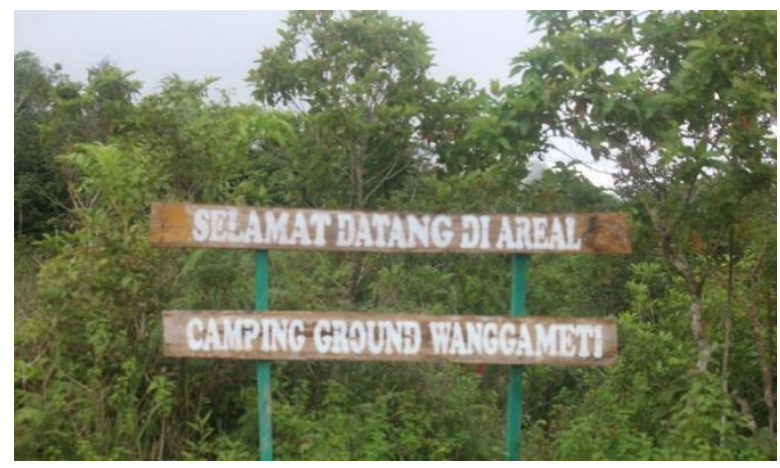

Gambar 2. Area Camping Ground Sumber : Dokumentasi Peneliti (2018)

\section{- Dataran Tinggi Katikuwai}

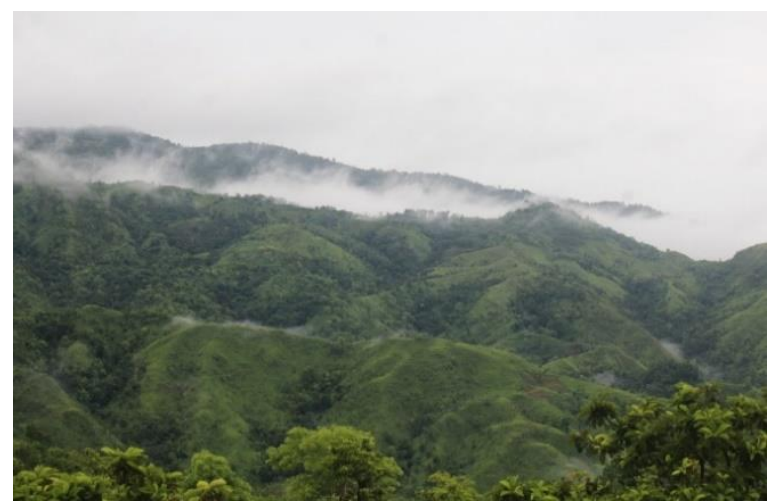

Gambar 3. Dataran Tinggi Katikuwai

Sumber : Dokumentasi Peneliti (2018)

Dataran tinggi Katikuwai (Gambar 3) berlokasi di desa Katikuwai yakni salah salah satu desa yang berada didalam kawasan TN Matalawa khususnya di kawasan Laiwangi Wanggameti. Di lokasi ini pengunjung akan menikmati keindahan landscape berupa bukit-bukit hijau yang didominasi oleh padang sabana. Pada musim hujan kawasan ini akan ditutupi dengan kabut yang sangat tebal. Lokasi ini dapat di akses melalui desa Katikuwai yang berjarak $87 \mathrm{~km}$ dari ibukota Kabupaten dengan waktu tempuh 4-5 jam menggunakan kendaran roda 2 maupun roda 4 .

\section{- Air Terjun}

Kawasan Laiwangi Wanggameti merupakan kawasan yang kaya akan sumberdaya air. Salah satunya adalah air terjun. Diketahui ada 4 sumber air terjun yang ada di kawasan ini, yakni air terjun Laputi, air terjun Wanggameti, air terjun Kahalatau dan air terjun Waikanabu. Dari keempat air terjun ini hanya air terjun Laputi yang telah dilakukan pengelolaan oleh pihak TN Matalawa melalui pembuatan shelter dan MCK (TN Matalawa 2017c). Sedangkan untuk air terjun yang lain baru sebatas pada proses survei.

Air terjun Laputi (Gambar 4) berada di desa Praing Kareha Kecamatan Tabundung yang berjarak sekitar $115 \mathrm{~km}$ dari ibukota Kabupaten. Untuk mencapai lokasi air terjun Laputi dapat menggunakan kendaraan roda 2 maupun roda 4 , dengan waktu tempuh berkisar 3-4 jam. Pintu masuk ke kawasan berada di depan kantor resort Praing Kareha. Dari jalan utama pengunjung akan melewati jalan berbatu yang berada di tengahtengah rumah penduduk selama kurang lebih 5 menit.

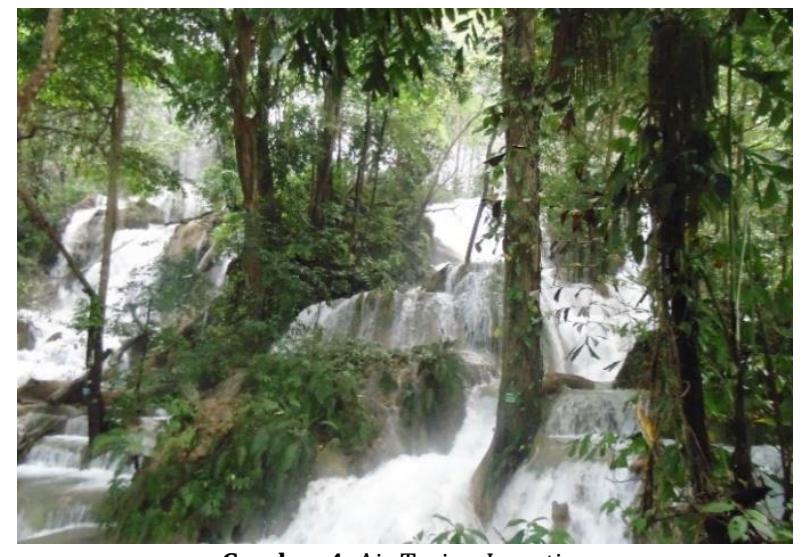

Gambar 4. Air Terjun Laputi Sumber : Dokumentasi Peneliti (2018)

\section{- Danau Laputi}

Danau ini lokasinya berdekatan dengan air terjun Laputi (Gambar 5). Namun untuk mengaksesnya pengunjung harus masuk melalui gerbang utama. Untuk dapat mengakses lokasi ini, pengunjung diwajibkan untuk melapor di kantor resort Praing Kareha yang berada sekitar 2-3 km dari gapura utama sekaligus untuk menyimpan kendaraan. Dari pintu masuk utama pengunjung akan berjalan kaki selama kurang lebih 20-30 menit melalui sebuah jalan beraspal yang kondisinya rusak.

Lokasi ini sangat mudah untuk di capai karena pihak pengelola sebelumnya telah membuat petunjuk arah ke danau Laputi. Danau Laputi 
dikelilingi oleh pepohonan yang sangat lebat dan didominasi oleh pohon-pohon dari famili Palmae. Suasana di lokasi sangat hening cocok bagi pengunjung yang ingin menenangkan diri sambal menikmati keindahan danau Laputi. Di Lokasi ini pengunjung dapat menikmati keindahan danau Laputi dengan bersantai, foto-foto atau aktivitas memberi makan belut air tawar yang menghuni danau ini.

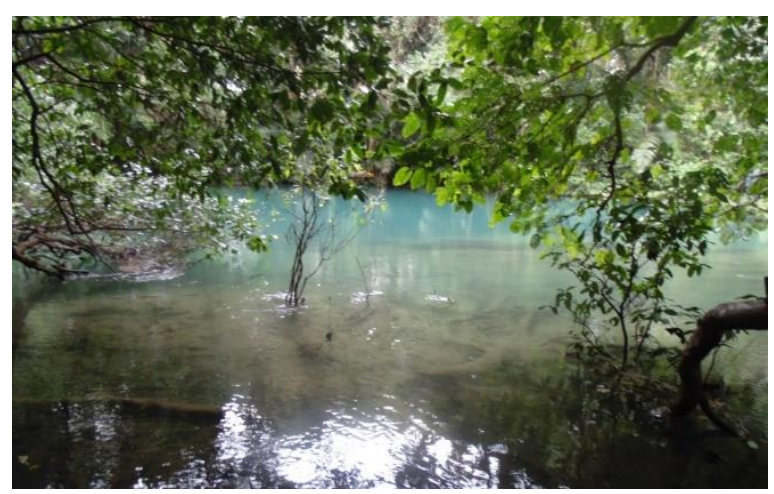

Gambar 5. Danau Laputi

Sumber : Dokumentasi Peneliti (2018)

\section{- Area Birdwatching}

Taman Nasional Matalawa memiliki kelimpahan burung yang sangat tinggi sehingga dapat direkomendasikan untuk aktivitas birdwatching. Salah satu lokasi yang baik untuk pengamatan burung adalah di desa Billa. Desa Billa adalah salah satu desa yang berada di kecamatan Tabundung. Desa ini berjarak 103 km dari ibukota Kabupaten. Lokasi pengamatan burung di desa Billa dapat diakses menggunakan kendaraan roda 2 dengan menempuh perjalanan dari ibukota kecamatan kurang lebih 1-1,5 jam. Kondisi jalan ke lokasi pengamatan masih kurang baik dan pada musim hujan jalannya sangat berlumpur sehingga akan mengganggu perjalanan.
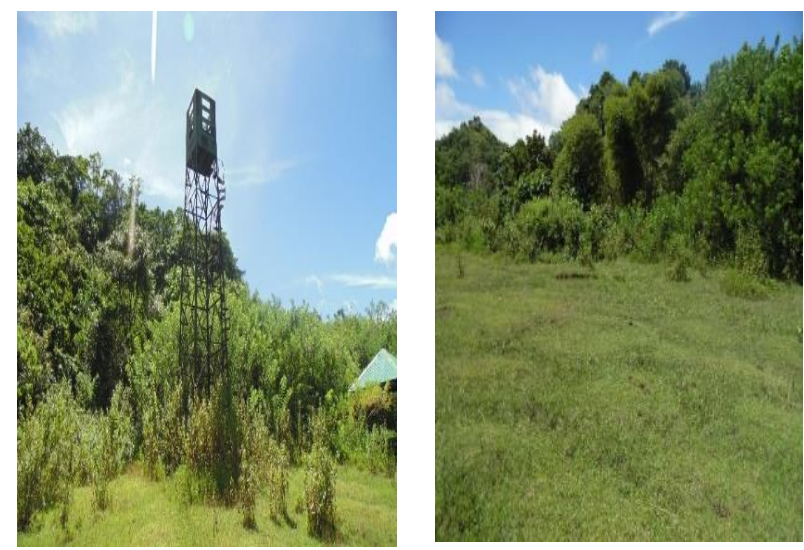

Gambar 6. Lokasi Birdwatching Sumber : Dokumentasi Peneliti (2018)

Perpaduan 2 ekosistem yang berbeda yakni kawasan hutan tertutup dan padang savana di lokasi birdwatching (Gambar 6) ini memberi suatu kemudahan untuk mengamati burung yang sedang terbang maupun yang bertengger. Dilokasi ini burung-burung yang dapat diamati antara lain kakatua-kecil jambul jingga, julang sumba, perkici pelangi, nuri bayan, nuri pipi merah, betet kepala paruh besar. Kakatua sumba biasa teramati keluar dari hutan tertutup dan melintasi padang pada rentang waktu 05.30-06.30 waktu setempat.

\section{b. Sarana Wisata}

Hasil penelitian menunjukkan bahwa sarana pendukung wisata yang telah ada di kawasan ini diantaranya papan informasi, papan larangan, shelter, menara pengamatan burung, area tracking, dan MCK. Semua fasilitas ini masih cukup baik, namun kurang perawatan. Lebih lanjut disekitar lokasi wisata tidak ditemukan adanya fasilitas penginapan (hotel atau homestay), tempat makan (restoran atau kafe), pusat souvenir, bank maupun tempat penukaran uang. Sarana dan prasarana wisata yang akan mendukung kegiatan wisata merupakan fasilitas yang akan membuat kegiatan wisata akan sesuai dengan yang diharapkan pengunjung. Namunbagi wisatawan dengan minat khusus keterbatasan tersebut tidak akan menjadi masalah. Hal ini sejalan denganpendapat Sekartjararini (2009) yang menyatakkan bahwa ecotourist dalam mencari sebuah pengalaman wisata, keterbatasan sarana dan prasarana umumnya tidak terlalu dipersoalkan.

c. Aksesibilitas

Kota Waingapu sebagai ibukota kabupaten Sumba Timur dapat diakses melalui jalur udara dan Laut. Jalur udara dilayani oleh beberapa maskapai penerbangan swasta nasional. Dengan waktu tempuh 1-1.5 jam melalui Kupang dan Denpasar. Sedangkan jalur laut dilayani oleh KM Awu - PT. Pelni dengan rute Benoa (Bali) Waingapu dengan waktu tempuh kurang lebih 36 jam. Selain itu dapat melalui jalur Kupang-EndeWaingapu dengan waktu tempuh kurang lebih 22 jam. Di Kota Waingapu terdapat 1 bandara yang melayani rute domestik yakni bandara Umbu Mehang Kunda dan 1 Pelabuhan laut yakni pelabuhan Nusantara.

Akses menuju kawasan hutan Laiwangi Wanggameti TN Matalawa dapat menggunakan kendaraan roda 2 dan roda 4 melalui : (1) Rute barat (melewati kecamatan Tabundung) dengan jarak $115 \mathrm{~km}$ dari kota Waingapu. Waktu yang diperlukan adalah sekitar 4-5 jam; (2) Rute timur (melewati kecamatan Matawai Lapawu) berjarak $73 \mathrm{~km}$ dari kota Waingapu dengan waktu tempuh 4-5 jam.

Infrastruktur jalan yang melalui kedua rute ini khususnya dari ibukota kabupaten sangat baik kondisinya. Hanya kondisi jalan yang menuju ke kawasan hutan Laiwangi Wanggameti berada dalam kondisi rusak ringan sampai dengan rusak berat. Jalan yang berada di dalam kawasan hutan 
Laiwangi Wanggameti umumnya berada dalam kondisi rusak berat.

d. Informasi dan Promosi

Pemberian informasi dan promosi terkait objek daya tarik wisata alam yang ada di TN Matalawa terus dilakukan oleh pihak pengelola dalam rangka memberikan informasi terkait keunggulan yang dimiliki kawasan. Dalam kurun waktu 2010-2014 telah dilakukan upaya untuk mempromosikan kawasan Laiwangi Wanggameti, yang pada saat itu masih berstatus sebagai TN Laiwangi Wanggameti melalui website www.tnlaiwangiwanggameti.com.

Setelah dilakukan penggabungan dengan TN Manupeu Tanadaru pada tahun 2016 upaya promosi terhadap potensi kawasan dilakukan melalui beberapa upaya diantaranya; (1)pembuatan website TN Matalawa dengan alamat https://tnmatalawa.com; (2) promosi melaui media sosial seperti facebook, instagram, twitter maupun youtube. Media sosial ini juga diterintegrasikan ke dalam satu aplikasi yang disebut Mame Matalawa; (3) pada tahun 2017 menyelanggarakan event lomba fotografi burung tingkat nasional yang diikuti oleh berbagai pecinta fotografi burung yang ada di Indonesia. Upaya ini juga sekaligus sebagai wadah promosi keberadaan TN Matalawa yang baru dibentuk pada tahun 2017; (4) penyebaran informasi potensi alam kawasan melalui poster, kalender, stiker, leaflet, dan buletin kakatua; (5) mengikuti pameran dan promosi konservasi alam melalui pameran pembangunan ditingkat kecamatan, kabupaten, dan provinsi (TN Matalawa 2017b).

\subsubsection{Potensi Demand}

Keberadaan demand erat kaitannya dengan kebutuhan manusia (people need) dan keinginan manusia (people want) atau motif untuk melakukan aktivitas. Adapun potensi demand yang dikaji dalam penelitian ini meliputi karakteristik, motivasi, serta kebutuhan calon pengunjung potensial.

a. Karakteristik Pengunjung Calon Potensial

Calon pengunjung potensial yang menjadi responden dalam penelitian ini berasal dari masyarakat lokal Sumba Timur dan masyarakat yang berasal dari luar Sumba Timurn yang tergabung dalam masyarakat pecinta wisata alam.Jumlah responden yang digunakan adalah sebanyak 100 orang yang dipilih secara purposive sampling (sengaja). Karakteristik pengunjung di tunjukkan pada Tabel 1.

Hasil penelitian menunjukkan bahwa karakteristik pengunjung potensial yang akan berkunjung ke kawasan Laiwangi Wanggameti didominasi oleh calon pengunjung perempuan, usia calon pengunjung secara keseluruhan berkisar antara 26-35 tahun, dengan pekerjaan dominan PNS/Polri. Selain itu, diketahui bahwa pendapatan calon pengunjung didominasi oleh pengunjung dengan kisaran pendapatanberkisar antara Rp2.000.000 Rp5.000.000, dominan mengeluarkan biaya wisata dalam setahun berkisar antara 0Rp500.000 dengan frekuensi wisata 4-10 kali dalam setahun.

Tabel 1. Karakteristik Calon Pengunjung Potensial

\begin{tabular}{|c|c|c|}
\hline Karakteristik & Kategori & Persentase \\
\hline \multirow[t]{2}{*}{ Jenis kelamin } & Laki-laki & 42 \\
\hline & Perempuan & 58 \\
\hline \multirow[t]{2}{*}{ Status } & Menikah & 26 \\
\hline & Belum menikah & 74 \\
\hline \multirow[t]{3}{*}{ Umur } & $19-25$ & 37 \\
\hline & $26-35$ & 48 \\
\hline & $\geq 36$ & 15 \\
\hline \multirow[t]{5}{*}{ Pendidikan } & SMA/ Sederajat & 15 \\
\hline & D3 & 10 \\
\hline & S1 & 67 \\
\hline & S2 & 7 \\
\hline & S3 & 1 \\
\hline \multirow[t]{14}{*}{ Pekerjaan } & PNS/Polri & 31 \\
\hline & Karyawan & 20 \\
\hline & swasta/BUMN & \\
\hline & Wiraswasta & 19 \\
\hline & Mahasiswa & 17 \\
\hline & Honorer & 2 \\
\hline & Pendeta & 1 \\
\hline & Jurnalis & 1 \\
\hline & Fasilitator & 2 \\
\hline & Experience consultant & \\
\hline & Freelance & 4 \\
\hline & Fotografer & 1 \\
\hline & Spesialis & 1 \\
\hline & & 1 \\
\hline \multirow{5}{*}{$\begin{array}{l}\text { Pendapatan per } \\
\text { bulan (Rp) }\end{array}$} & $<500$ ribu & 10 \\
\hline & 500 ribu - 1 juta & 9 \\
\hline & 1 juta- 2 juta & 26 \\
\hline & 2 juta- 5 juta & 38 \\
\hline & $>5$ juta & 17 \\
\hline \multirow{5}{*}{$\begin{array}{l}\text { Frekuensi Wisata } \\
\text { (kali/tahun) }\end{array}$} & 1 & 11 \\
\hline & 2 & 33 \\
\hline & 3 & 11 \\
\hline & $4-10$ & 38 \\
\hline & $>10$ & 7 \\
\hline \multirow[t]{4}{*}{ Biaya Wisata (Rp) } & $0-500$ ribu & 40 \\
\hline & 600 ribu - 2 juta & 37 \\
\hline & 3 juta- 5 juta & 8 \\
\hline & $>6$ juta & 15 \\
\hline
\end{tabular}

b. Motivasi Calon Pengunjung Potensial.

Hasil penelitian menunjukkan bahwa motivasi calon pengunjung untuk melakukan wisata di lokasi ini cukup bervariasi. Secara umum yang menjadi motivasi pengunjung ke kawasan ini antara lain untuk rekreasi, menikmati keindahan alam terutama flora, fauna, air terjun, ekosistem savana dan atraksi satwa liar seperti burung. Selain itu, ada pula yang ingin menyalurkan hobi seperti pendakian dan penelusuran hutan serta ada yang ingin belajar tentang budaya sumba.

Motivasi calon pengunjung lainnya adalah untuk turut serta dalam mengkampanyekan budaya cinta terhadap alam, memberikan pendidikan cinta lingkungan kepada anak-anak, serta ada juga yang ingin datang ke kawasan ini hanya untuk mencari suasana wisata alam yang baru. Hal ini sejalan dengan (Alghamdi 2007) yang 
menyatakan bahwa motivasi dalam melakukan aktivitas wisata didorong oleh faktor pendorong berwisata (push factor) seperti dorongan untuk menambah pengetahuan (knowledge), melepaskan diri dari rutinitas sehari-hari (escape motives), untuk menikamti keindahan alam (enjoying natural resources) maupun untuk melakukan perjalanan ke lokasi wisata baru (adventure)

Motivasi merupakan hal yang penting dalam mengambil keputusan untuk melakukan aktivitas wisata. Sebagimana yang dikutip dari Pitana dan Gayatri (2005) motivasi merupakan trigger dari proses perjalanan wisata yang sering tidak disadari oleh seorang wisatawan yang mendorongnya untuk melakukan sesuatu guna menemui kebutuhan atau keinginan untuk melakukan wisata. Sejalan dengan hal diatas Kotler dan Keller (2009) mengungkapkan juga bahwa keputusan untuk melakukan sebuah perjalanan wisata pada dasarnya sama dengan keputusan pembelian yakni mengeluarkan uang untuk mendapatkan kepuasan.

c. Kebutuhan Calon Pengunjung

Dalam menunjang aktivitas wisata yang akan dilakukan oleh calon pengunjung dalam kawasan Laiwangi Wanggameti, maka sejumlah sarana pendukung wisata harus disiapkan oleh pihak pengelola. Hasil penelitian memberikan gambaran bahwa sarana pendukung yang dibutuhkan oleh calon pengunjung lokal antara lain penginapan, tempat makan/minum, tempat ibadah, toilet. Ada pula yang menginginkan agar akses jalan diperbaiki, pemandu yang informatif, kebutuhan akan pusat informasi terkait TN Matalawa (tourism center), sistem pembayaran tiket yang mudah dan praktis, kebutuhan akan keamanan, map tracking, tempat sampah serta sarana penunjang seperti papan informasi, interpretasi dan papan larangan.

\subsection{Potensi Willingness To Pay (WTP) Calon Pengunjung Potensial Lokal}

Hasil penelitian terkait keinginan membayar (WTP) calon pengunjung potensial lokal untuk tarif tiket menunjukkan bahwa 100 persen calon pengunjung bersedia untuk membayar (Tabel 2). Secara umum alasan mereka bersedia membayar adalah untuk memberi dukungan terhadap berbagai upaya pengelolaan kawasan yang dilakukan pihak pengelola seperti untuk biaya operasional perawatan sarana dan prasarana, maupun dapat digunakan untuk pengembangan berbagai potensi alam yang dimiliki oleh kawasan. Selain itu, adapula yang menyatakkan bahwa dengan membayar tarif masuk secara tidak langsung turut merawat dan menjaga alam.

Nilai WTP untuk tarif tiket yang diberlakukan untuk pengunjung lokal cukup bervariasi yakni dari kisaran Rp5.000 sampai dengan Rp20.000.
Pada Tabel 3 dapat dilihat rataan WTP tiket calon pengunjung lokal terkait konsep ekowisata yang akan dikembangkan di kawasan hutan Laiwangi Wanggameti.

Tabel 2. Kesediaan membayar (WTP) pengunjung lokal Terhadap tarif tiket masuk

\begin{tabular}{ccc}
\hline \hline $\begin{array}{c}\text { Kesediaan } \\
\text { Membayar }\end{array}$ & $\begin{array}{c}\text { Frekuensi } \\
\text { (orang) }\end{array}$ & Persentase \\
\hline Ya & 50 & 100 \\
Tidak & 0 & 0 \\
\hline Total & 50 & 100 \\
\hline Sumber : Data Primer Diolah (2018)
\end{tabular}

Tabel 3. Rataan WTP Tiket Calon Pengunjung Lokal

\begin{tabular}{cccc}
\hline \hline \multirow{2}{*}{$\begin{array}{c}\text { Nilai WTP } \\
\text { (Rp/tiket } \\
\text { / } \\
\text { orang) } \\
\text { (a) }\end{array}$} & $\begin{array}{c}\text { Frekuensi } \\
\text { (orang) } \\
\text { (b) }\end{array}$ & Persentase & $\begin{array}{c}\text { Rataan } \\
\text { WTP } \\
\text { (Rp) }\end{array}$ \\
\hline 5.000 & 22 & $\mathbf{c}=(\mathbf{b} / \mathbf{n} * \mathbf{)} \mathbf{x}$ & $\mathbf{d}=\mathbf{( a \mathbf { x c } ) / \mathbf { 1 0 0 }}$ \\
10.000 & 26 & 22 & 1.100 \\
15.000 & 13 & 26 & 2.600 \\
20.000 & 39 & 13 & 1.950 \\
\hline Total & 100 & 39 & 7.800 \\
\hline *n $=50$ (jumlah responden) & 100 & $\mathbf{1 3 . 4 5 0}$ \\
Sumber: Data Primer Diolah (2018) &
\end{tabular}

Hasil penelitian terkait kesediaan membayar calon pengunjung potensial menunjukkan bahwa nilai rataan WTP pengunjung adalah sebesar Rp13.450 per orang per tiket. Seperti yang ditunjukkan pada Tabel 3. Besaran nilai WTP diatas tentu dapat direkomendasikan sebagai besaran tiket yang dapat diberlakukan di kawasan Laiwangi Wanggameti, karena jika dilihat dari besaran tiket yang diberlakukan sekarang (Rp5.000/orang/tiket) rataan WTP hasil penelitian jauh lebih besar. Namun apabila besaran nilai WTP ini ditetapkan sebagai harga tiket, maka tidak semua pengunjung akan bersedia untuk membayar tiket dengan nilai tersebut. Karena ada sekitar 48\% calon pengunjung yang tidak akan membayar yakni calon pengunjung dengan WTP Rp5.000 dan Rp10.000 atau pengunjung yang memiliki WTP dibawah nilai rataan WTP. Hal ini tentu akan menyebabkan terjadinya penurunan jumlah pengunjung. Oleh karena itu, diperlukan estimasi jumlah penerimaan berdasarkan rataan WTP pengunjung serta harga tiket yang berlaku sekarang untuk melihat nilai WTP manakah yang dapat memberikan penerimaan yang optimal. Tabel 4 menunjukkan estimasi penerimaan berdasarkan tarif tiket yang berlaku sekarang dan rataan WTP pengunjung.

Pada Tabel 4 terlihat bahwa total estimasi penerimaan terbesar dari retribusi tiket masuk ke kawasan Laiwangi Wanggameti adalah pada penerapan tiket sebesar Rp13.450 per tiket per orang atau sesuai nilai rataan WTP pengunjung. Dengan estimasi penerimaan per tahunnya mencapai Rp60.148.400. Penerimaan ini jauh 
lebih besar jika dibandingkan dengan penerapan harga tiket yang berlaku sekarang yakni Rp5 000 per tiket per orang. Pada Tabel 4 terlihat bahwa dengan penerapan harga tiket sebesar Rp5.000 jumlah pengunjung akan meningkat dari 22\% menjadi 100\% karena pengunjung dengan WTP diatas Rp5.000 akan turut membayar. Namun jika dilihat dari estimasi penerimaan, memiliki estimasi penerimaan yang lebih rendah jika dibandingkan dengan penerapan harga tiket sesuai rataan WTP pengunjung.

Tabel 4. Estimasi penerimaan dengan penerapan harga tiket eksisting dan rataan WTP pengunjung

\begin{tabular}{cccc}
\hline $\begin{array}{c}\text { Harga } \\
\text { tiket } \\
\text { (Rp/tiket } \\
\text { /orang) }\end{array}$ & $\begin{array}{c}\% \\
\text { Pengunjung }\end{array}$ & $\begin{array}{c}\Sigma \\
\text { Pengunjung } \\
\text { (orang) }\end{array}$ & $\begin{array}{c}\text { Estimasi } \\
\text { penerimaan } \\
\text { (Rp/tahun) } \\
\text { d = a x c }\end{array}$ \\
\hline 5.000 & 100 & c = b x N* & \\
13.450 & 52 & 8.600 & 43.000 .000 \\
\hline
\end{tabular}

${ }^{*} \mathrm{~N}=86$ (jumlah pengunjung tahun 2017)

Data Primer Diolah (2018)

Estimasi penerimaan sebesar

Rp60.148.400 yang diperoleh dari total kesediaan membayar tersebut adalah potensi nilai ekonomi yang dimiliki oleh kawasan Laiwangi Wanggameti yang dapat berkontribusi terhadap penerimaan negara bukan pajak dari sektor kehutanan. Namun pada tahap operasional, nilai ini dapat menjadi lebih tinggi atau lebih rendah tergantung jumlah kunjungan wisatawan yang berkunjung ke kawasan ini.

Dari keseluruhan hasil penilaian WTP terlihat bahwa rataan WTP pengunjung berada di atas harga tiket yang berlaku sekarang di TN Matalawa. Dimana harga tiket yang diberlakukan sekarang adalah Rp5.000 per tiket per orang sesuai PP Nomor 14 tahun 2014 tentang PNBP sektor kehutanan. Hal ini memberikan gambaran bahwa pengunjung memiliki keinginan untuk membayar lebih dari harga tiket yang berlaku sekarang. Sebagai sebuah potensi penerimaan untuk peningkatanPBNP bagi taman nasional, maka nilai rataan WTP dapat dijadikan sebagai bahan pertimbangan dalam penyusunan arahan kebijakan pengembangan ekowisata di kawasan ini.Khususnya dalam meningkatkan jumlah kunjungan dan lama waktu pengunjung di kawasan ini.

Penerimaan dari kegiatan ekowisata dapat memberikan tambahan dana bagi berbagai upaya konservasi yang dilakukan oleh pihak pengelola taman nasional Matalawa untuk keberlanjutan sumberdaya alam di kawasan ini pada masa yang akan datang. Hal ini sejalan dengan pernyataan Lindberg dkk(1996) maupun oleh Ekayani dan Nuva (2013) yang menyatakkan bahwa ekowisata memberikan dukungan finansial untuk perlindungan dan pengelolaan kawasan yang masih alami serta memberikan insentif ekonomi untuk berbagai upaya konservasi didalam kawasan konservasi. Ditambahkan pula oleh KLH (2013) yang berpendapat bahwa konservasi biodiversitas ditujukan untuk melindungi ketersediaan barang dan jasa lingkungan yang berkelanjutan. Sehingga sumber pendanaan untuk skema pembiayaan yang berkelanjutan dapat diperoleh melalui pariwisata berbasiskan pungutan (tourism based-fees).

\subsection{Arahan Strategi Pengembangan Ekowisata di Segmen Laiwangi Wanggameti}

Tabel 5. Faktor internal dan eksternal Kawasan Laiwangi Wanggameti

\begin{tabular}{|c|c|c|}
\hline \multicolumn{3}{|c|}{ Internal } \\
\hline No & $\begin{array}{l}\text { Kekuatan } \\
\text { (Strength) }\end{array}$ & $\begin{array}{l}\text { Kelemahan } \\
\text { (Weakness) }\end{array}$ \\
\hline 1. & $\begin{array}{l}\text { Memiliki objek daya tarik } \\
\text { wisata alam yang layak } \\
\text { (ODTWA)_ untuk kegiatan } \\
\text { ekowisata }\end{array}$ & $\begin{array}{l}\text { Aksesibilitas dan } \\
\text { infrastruktur pendukung } \\
\text { yang belum memadai } \\
\text { (misalnya : jalan, jaringan } \\
\text { telekomunikasi, listrik) }\end{array}$ \\
\hline 2. & $\begin{array}{l}\text { Status pengelolaan } \\
\text { kawasan yang sudah jelas }\end{array}$ & $\begin{array}{l}\text { Topografi lokasi yang } \\
\text { berbukit dan kemiringan } \\
\text { lereng yang curam }\end{array}$ \\
\hline 3 & $\begin{array}{l}\text { Regulasi yang mendukung } \\
\text { dalam pengembangan } \\
\text { ekowisata }\end{array}$ & $\begin{array}{l}\text { Persoalan batas kawasan } \\
\text { di beberapa desa sekitar } \\
\text { yang belum tuntas }\end{array}$ \\
\hline 4. & $\begin{array}{l}\text { Potensi sumber daya } \\
\text { manusia pengelola taman } \\
\text { nasional yang berkualitas }\end{array}$ & $\begin{array}{l}\text { Kurangnya sosialisasi/ } \\
\text { edukasi terkait zonasi } \\
\text { kawasan pada beberapa } \\
\text { kelompok masyarakat } \\
\text { yang berada di sekitar } \\
\text { kawasan }\end{array}$ \\
\hline 5. & $\begin{array}{l}\text { Tersedianya data potensi } \\
\text { sumber daya alam } \\
\text { kawasan }\end{array}$ & \\
\hline 6. & $\begin{array}{l}\text { Memiliki dokumen } \\
\text { perencanaan yang sesuai } \\
\text { dengan status kawasan }\end{array}$ & \\
\hline 7. & $\begin{array}{l}\text { Promosi yang baik dari } \\
\text { pengelola terkait potensi } \\
\text { kawasan }\end{array}$ & \\
\hline 8. & $\begin{array}{l}\text { Ketegasan terhadap } \\
\text { pelanggaran yang terjadi } \\
\text { di dalam kawasan }\end{array}$ & \\
\hline
\end{tabular}

\begin{tabular}{|c|c|c|}
\hline \multicolumn{3}{|c|}{ Eksternal } \\
\hline No & $\begin{array}{c}\text { Peluang } \\
\text { (Oppurtunities) }\end{array}$ & $\begin{array}{c}\text { Ancaman } \\
\text { (Treath) }\end{array}$ \\
\hline 1. & Potensi WTP & $\begin{array}{l}\text { Ketergantungan } \\
\text { masyarakat di sekitar } \\
\text { kawasan terhadap sumber } \\
\text { daya hutan }\end{array}$ \\
\hline 2. & $\begin{array}{l}\text { Dukungan pengembangan } \\
\text { ekowisata dari } \\
\text { masyarakat di sekitar } \\
\text { kawasan }\end{array}$ & $\begin{array}{l}\text { Gangguan dari aktivitas } \\
\text { masyarakat seperti } \\
\text { perambahan, penebangan, } \\
\text { perburuan satwa liar } \\
\text { maupun kebakaran }\end{array}$ \\
\hline 3. & $\begin{array}{l}\text { Adanya peningkatan tren } \\
\text { wisata alam di Kota } \\
\text { Waingapu }\end{array}$ & $\begin{array}{l}\text { Pemahaman masyarakat } \\
\text { yang masih rendah } \\
\text { terhadap batas kawasan }\end{array}$ \\
\hline 4. & $\begin{array}{l}\text { Belum ada lokasi } \\
\text { ekowisata berbasis } \\
\text { kawasan hutan }\end{array}$ & \\
\hline 5. & $\begin{array}{l}\text { Usaha wisata alam yang } \\
\text { belum ada }\end{array}$ & \\
\hline
\end{tabular}

Penentuan strategi pengembangan ekowisata di TN Matalawa khususnya di kawasan Laiwangi Wanggameti dilakukan dengan 
menggunakan analisis SWOT. Analisis SWOT digunakan sebagai instrumen dalam perencanaan strategi dengan menganalisis faktor-faktor internal yang ada dalam kawasan yakni kekuatan dan kelemahan serta faktor-faktor eksternal seperti peluang dan ancaman. Faktor-faktor ini diidentifikasi melalui wawancara mendalam dengan key person yang berasal dari TN Matalawa maupun dari beberapa stakeholder terkait serta dari hasil observasi selama di lapangan. Hasil identifikasi faktor internal dan eksternal dapat di lihat pada Tabel 5.

Hasil evaluasi faktor internal (IFAS) menunjukkan bahwa pengelola TN Matalawa telah memanfaatkan kekuatan dengan baik serta pada sisi yang lain telah juga mampu meminimalkan kelemahan secara bersama. Hal ini ditunjukkan dengan nilai total skor IFAS sebesar 3.379. Ini berlaku juga pada hasil evaluasi faktor eksternal (EFAS), dimana total skornya adalah 3.00. Dengan kata lain pengelola TN Matalawa telah mampu memanfaatkan peluang yang ada serta meminimalkan ancaman.

Dari keseluruhan hasil di atas adapun arahan strategi yang dapat diterapkan dalam pengembangan ekowisata di kawasan hutan Laiwangi Wanggameti diarahkan untukmendukung kebijakan pertumbuhan yang agresifdengan menggunakan 4 kemungkinan strategi yakni strategi S-O (StrengthOppurtunities), Strategi W-O (WeaknessesOppurtunities), Strategi S-T (Strength - Treath) dan Strategi W-T (Weaknesses- Treath). Dengan strategi sebagai berikut:

1. Optimalisasi pemanfaatan potensi ODTW yang dimiliki untuk pengembangan ekowisata.

2. Memberikan ruang keterlibatan masyarakat lokal dalam pengembangan ekowisata.

3. Optimalisasi pemanfaatan potensi ODTW yang dimiliki untuk pengembangan ekowisata.

4. Optimalisasi sosialiasi secara reguler kepada masyarakat sekitar kawasan terkait fungsi kawasan Laiwangi Wanggameti sebagai kawasan konservasi.

5. Pengembangan produk wisata minat khusus.

6. Penyelesaian batas kawasan dengan melibatkan semua stakeholder yang berkepentingan didalamnya.

\section{Kesimpulan}

1. Potensi supply dan demand ekowisata kawasan Laiwangi Wanggameti terdiri dari : (1) atraksi biologi dan fisik; (2) sarana wisata; (3) Lokasi dapat di akses melalui 2 pintu utama yakni melalui kecamatan Matawai Lapawu dan Tabundung; (4) informasi dan promosi kawasan dapat diakses melalui website TN Matalawa maupun melalui media sosial lainnya; (5) karakteristik pengunjung didominasi oleh calon pengunjung perempuan, usia calon pengunjung secara keseluruhan berkisar antara 19-35 tahun, dengan pekerjaan dominan PNS/Polri;(6) kebutuhan pengunjung antara lain tempat, MCK, bank, pusat informasi terkait TN Matalawa (tourism center), sistem pembayaran tiket yang mudah dan praktis, kebutuhan akan keamanan, map tracking, tempat sampah serta sarana penunjang seperti papan informasi, interpretasi dan larangan ; (7) motivasi paling dominan untuk berkunjung ke kawasan Laiwangi Wanggameti adalah untuk rekreasi

2. Rataan WTP calon pengunjung yang dapat direkomendasikan bagi pengelola sebesar Rp.13.450 per orang per tiket.

3. Arahan strategi pengembangan ekowisata di kawasan Laiwangi Wanggameti antara lain : (1) Optimalisasi pemanfaatan potensi ODTW yang dimiliki untuk pengembangan ekowisata; (2)memberikan ruang keterlibatan masyarakat lokal dalam pengembangan ekowisata; (3)optimalisasi pemanfaatan potensi ODTW yang dimiliki untuk pengembangan ekowisata; (4) optimalisasi sosialiasi secara reguler kepada masyarakat sekitar kawasan terkait fungsi kawasan Laiwangi Wanggameti sebagai kawasan konservasi; (5) pengembangan produk wisata minat khusus; (6) penyelesaian batas kawasan dengan melibatkan semua stakeholder yang berkepentingan didalamnya.

\section{DAFTAR PUSTAKA}

Alghamdi, A.,(2007),Explicit and implicit motivation towards outbound tourism: a study of Saudi tourists. PhD Thesis. University Of Glasgow School of BusinessManagement. Glasgow.

Birgantoto, BA., Nurrochmat, D.R., (2007), Pemanfaatan sumberdaya hutan oleh masyarakat di KPH Banyuwangi Utara, JMHT, 8(3),172-181.

Ekayani, M., Nuva., Yasmin, R.K., Shaffitri, L.R., Idris B.T., Taman Nasional untuk siapa? tantangan membangun wisata alam berbasis masyarakat di Taman Nasional Gunung Halimun Salak, 2014,Risalah Kebijakan Pertanian dan Lingkungan, $1(1), 46-52$.

Ekayani, M., dan Nuva., 2013, Economic Ecotourism. Di dalamOppurtunities andChallenges of Ecotourism in ASEAN Countrie, Jungmin Publishing Co, Seoul.

Husama., Hudha, A.M., (2018), Evaluasi Implementasi Prinsip Ekowisata Berbasis Masyarakat Dalam Pengelolaan Clungup Mangrove,Jurnal Pengelolaan Sumberdaya Alam dan Lingkungan, 8(1), 86-95.

Jalani, J.O., (2012), Local people's perception on the impacts and importance of ecotourism in Sabang, Palawan, Phillipines,Procedia- Social and Behavioral Sciences, 57, 247-254.

Lindberg, K., Enriquez, J., Sproule, K., 1996, Ecotourism quitioned case study from Belize,Annals of Tourism Research, 23 (3), 543-562.

Kadir A., Awang, S.A., Purwanto RH., Poedjirahajoe E., (2012), Analisis kondisi ekonomi masyarakat sekitar Taman Nasional Bantimurung Bulusaraung Provinsi Sulawesi Selatan,J. Manusia dan Lingkungan, 19 (1), 1-11. 
Karsudi, Soekmadi R., Kartodiharjo, H., (2010), Strategi pengembangan ekowisata di Kabupaten Yapen Propinsi Papua, JMHT, 16(3),148-154.

[KLH] Kementerian Lingkungan Hidup, 2013, Media Briefing JasaLingkungan.[internet]. [diunduh 2018 Apr 18]. Tersedia pada:http://www.menlh.go.id/media-briefing pembayaran-jasa-lingkungan/.

Kotler, P., Keller, K.L., (2009),Manajemen Pemasaran Edisi 13, Yogyakarta, Erlangga

Nurrani L., Tabba S., (2013), Persepsi dan ketergantungan masyarakat terhadap sumberdaya alam Taman Nasional Akatajawe Lolobata di Propinsi Maluku Utara,Jurnal Penelitian Sosial dan Ekonomi Kehutanan, 10(1):61-73

Pitana, I.G., Gayatri, P.G., (2005),Sosiologi Pariwisata, Andi Offset, Yogyakarta.

Purwanto, S., Syaufina, L., Gunawan, A., (2014), Kajian potensi dan daya dukung Taman Wisata Alam Bukit Kelam untuk strategi pengembangan ekowisata,Jurnal Pengelolaan Sumberdaya Alam dan Lingkungan, 4(2),119-125.

TN Matalawa.,(2017a),Statistik Balai Taman Nasional Matalawa,Balai Taman Nasional Matalawa, Waingapu.
TN Matalawa., (2017b). RPJP TN Matalawa 20182027.Balai Taman Nasional Matalawa, Waingapu.

TNLW., (2013), Statistik Taman Nasional Laiwangi Wanggameti, Taman Nasional Laiwangi Wanggameyi, Waingapu.

[TIES] The International Of Ecotourism Society., (2015), Ecotourism Principles Revision. [Internet], [diunduh 2017 Jun 01], Tersedia pada: http://www.ecotourism.org/news/tiesannounces-ecotourism-principles-revision.

Widodo, M.L., Soekmadi R., Arifin HS.,(2018), Analisis Stakeholder Dalam Pengembangan Ekowisata Di Taman Nasional Betung Kerihun Kabupaten Kapuas Hulu,Jurnal Pengelolaan Sumberdaya Alam dan Lingkungan, 8(1), 55-61.

Wiyanto, T.,(2011), Pengelolaan Taman Nasional. [Internet].[diunduh 2017 Mar 29]. Tersedia pada http://forester85.co.id/2011/06/ -pengelolaantaman-nasional.html 4/4/2017.

Yuniarti, E., Soekmadi, R., Arifin, H.S., Noorachmat.,(2018), Analisis Potensi Ekowisata Heart Of Borneo Di Taman Nasional Betung Kerihun Kabupaten Kapuas Hulu. Jurnal Pengelolaan Sumberdaya Alam dan Lingkungan, 8(1), 44-54. 